\title{
Multiple Order-up-to Policy for Mitigating Bullwhip Effect in Supply Chain Network
}

\author{
Anupam Keshari ${ }^{\mathrm{a}^{*}}$, Nishikant Mishra ${ }^{\mathrm{b}}$, Nagesh Shukla ${ }^{\mathrm{c}}$, Steve McGuire ${ }^{\mathrm{d}}$ and Sangeeta \\ Khorana \\ ${ }^{a}$ Department of Mechanical Engineering, MNNIT, Allahabad, India \\ ${ }^{b}$ Hull University Business School, University of Hull, United Kingdom. \\ ${ }^{c}$ SMART Infrastructure Facility, Faculty of Engineering and Information Sciences, University of \\ Wollongong, Wollongong, Australia, \\ ${ }^{d}$ School of Business, Management and Economics, University of Sussex, Sussex UK \\ ${ }^{e}$ Bournemouth University Business School, Bournemouth University, Bournemouth, UK \\ * Corresponding author
}

This is a post-peer-review, pre-copyedit version of an article published in Annals of operations research. The final publication is available at Springer via https:// doi.org/10.1007/s10479-017-2527-y 


\begin{abstract}
This paper proposes a multiple order-up-to policy based inventory replenishment scheme to mitigate the bullwhip effect in a multi-stage supply chain scenario, where various transportation modes are available between the supply chain (SC) participants. The proposed policy is similar to the fixed order-up-to policy approach where replenishment decision "how much to order" is made periodically on the basis of the pre-decided order-up-to inventory level. In the proposed policy, optimal multiple order-up-to levels are assigned to each SC participants, which provides decision making reference point for deciding the transportation related order quantity. Subsequently, a mathematical model is established to define optimal multiple order-up-to levels for each SC participants that aims to maximize overall profit from the SC network. In parallel, the model ensures the control over supply chain pipeline inventory, high satisfaction of customer demand and enables timely utilization of available transportation modes. Findings from the various numerical datasets including stochastic customer demand and lead times validate that the proposed optimal multiple order-up-to policy based inventory replenishment scheme can be a viable alternative for mitigating the bullwhip effect and well-coordinated SC. Moreover, determining the multiple order-up-to levels is a NP hard combinatorial optimization problem. It is found that the implementation of new emerging optimization algorithm named Bacterial Foraging Algorithm (BFA) has presented superior optimization performances. The robustness and applicability of the BFA algorithm are further validated statistically by employing the percentage heuristic gap and two-way ANOVA analysis.
\end{abstract}

Keywords: Bullwhip Effect; Optimal Order-up-to Inventory Level; Bacterial Foraging Algorithm; Supply Chain. 


\section{Introduction}

Logistics operations and the related decisions to ensure uninterrupted and timely product flow across different segments of the supply chain (SC) are of paramount importance. At each stage of the SC, the management of product flow depends on various issues such as inventory stocks, replenishment order quantities and utilization of efficient transportation facilities. The SC participants which are mutually dependent entities are equally significant in maintaining an uninterrupted flow of products across different stages of the SC. This follows from the fact that replenishment decisions of the participants imposes direct and indirect effects on the replenishment or manufacturing decisions of upstream SC members. However, when decisions have indirect and delayed feedback effects, it becomes difficult to control the dynamics of the material flows. Thus, the entire product flow management is subject to coordination risk as this may trigger instability in the SC product flow (Croson et al., 2005). One prominent outcome of this instability in the SC is the bullwhip effect, which is the main focus of this paper.

The bullwhip effect refers to the phenomenon where variability of orders in the SC increases as one moves closer to the source of production (Metters, 1997; Yan and Katok, 2006). This suggests that orders on suppliers tend to have a larger variance than sales to buyers. As a result, the distortion propagates up-stream in an amplified form (Bray and Mendelson, 2012; Lee et al. $1997 \mathrm{a}, \mathrm{b}$ ). Inaccurate estimation of actual demand and the distortion of demand information from downstream to upstream end of the SC can increase the overall SC cost. The main consequences of distortions are observed in manufacturing as disrupted production schedules, higher rawmaterial costs and overtime expenses. Studies also find that the negative effects on the SC are in the form of excessive inventories in SC pipeline, uncertain production planning, unsatisfactory customer service, and higher shipping costs (Lee et al., 1997 a. b.; Chen et al., 1998). Recent work highlighting the effect of global financial crisis on SC management suggests that manufacturers and wholesalers are slow in responding to changing demand conditions (Dooley, Yan, Mohan and Gopalakrishnan, 2010). This emphasises that bullwhip effect minimization is critical and of paramount importance for ensuring coordination between replenishment programs of the SC participants (Cachon, Randall and Schmidt, 2007). Within this context, researchers and practitioners in production planning are currently examining various alternatives to integrate aspects of the SC as a whole rather than as a group of individually distributed entities to establish proper coordination between the various SC participants. 
Current research on the bullwhip effect can be broadly classified into two streams: first, work that analyses the bullwhip effect; and, second, efforts to solve the bullwhip effect problem in the SC. Nienhaus, Ziegenbein and Schoensleben (2006) attribute the bullwhip effect to human behaviour which involves over-ordering and panic behaviour due to stock depletion. Croson and Donohue (2006) demonstrate that biased decisions by the SC participants create bullwhip effect in the SC. Oliva and Goncalves (2005) also report similar results and confirm the above findings. Dooley et al. (2009) comment on the bullwhip effect in SCs and suggest that human agency and decision bias cannot be eliminated in the decision-making process. Simchi-Levi et al. (2008), Chopra and Meindl, (2001) report three major factors behind the bullwhip effect which include: (a) biased demand information from downstream SC members; (b) delayed information transferring; and, (c) unsuitable logistic operations. Lee et al. (2004a) argue that the distortion of demand information in the SC inherently causes the bullwhip effect, and that demand signal processing, lead time of replenishment, price fluctuations, order batching and rationing game contribute to the bullwhip effect generation. Niranjan, Metri and Aggarwal (2009), Lee et al. (1997a, 2000), and Chen et al. $(2000 \mathrm{a}, \mathrm{b})$ propose various statistical methodologies to quantify the magnitude of variance amplification in the SC. In a recent survey, Shan et al. (2013) investigated the bullwhip effect in China using data on over 1200 companies. Their results represent that more than twothirds of the companies have exhibited the bullwhip effect. The measured approach proposed in the existing literature have supported to mitigate the bullwhip effect intensity. The intensity of the bullwhip effect in investigated companies has declined during the period from 2002 to 2009.

The second stream of research, which focuses on resolving the bullwhip effect problem in the SC, has also been prominent. For instance, Ouyang and Daganzo (2006) suggest that accounting for future orders in existing ordering policies can mitigate the bullwhip effect. Dejonchheere et al. (2003) propose a control theory approach to quantify the bullwhip effect. Çetinkaya and Lee (2000) suggest Vendor-Managed Inventory (VMI) to mitigate the bullwhip effect, which authorizes the supplier to manage the inventory for each associated retailer. Cachon (1999) presents a scheduled ordering policy to manage SC demand variability. In this study, they observed that the lengthened order interval and increased batch size can decline demand variance in the upstream member. O'Donnell et al. (2006) suggest an ordering policy based replenishment program to track the demand pattern at each stage of the SC, though this leads to higher inventories in the long run.

Kristianto et al.(2012) presented adaptive fuzzy control application to support a vendor managed inventory (VMI). The adaptive fuzzy VMI control surpasses fuzzy VMI control and traditional VMI in terms of mitigating the bullwhip effect and lower delivery overshoots and backorders. 
Li (2012) advocated that limited information sharing increases the difficulty of reducing the bullwhip effect and leads to inefficient supply chain management. His research work explored new ways to reduce the bullwhip effect in supply chain systems that face uncertainties with respect to information sharing.

Yungao et al. (2012) presented a study on forecasting techniques for the product order and inventory lever prediction. They derived the analytical expressions of the bullwhip effect on product orders and inventory using minimum mean-squared error, moving average and exponential smoothing forecasting techniques. The research concludes the conditions under which the three forecasting techniques (minimum mean-squared error, moving average and exponential smoothing) can be chosen to minimize the bullwhip effect.

Recently, Dominguez et al. (2014) conducted a study to compare the bullwhip effect on a serial and a complex supply chain network (SCN). Responses of both SCNs for two different demand scenario such as stationary demand and an impulse demand is studied. Devika et al. (2016) optimised the bullwhip effect and net stock amplification in the case of a three-stage supply chain under centralised and decentralised scenarios. The causes for bullwhip effect and net stock amplification were modelled using response surface methodology and a multi-objective evolutionary optimisation was proposed to minimise the negative effects. Seles et al (2016) documented a study on understanding the green bullwhip effect in a context of automotive green supply chain management (GSCM) in Brazil. De Almeida (2015) reviewed literature on the role of trust and collaboration that can lead to the mitigation of bullwhip effect in SCM. The results of this review highlighted the lack of studies addressing behavioural aspects to reduce bullwhip effect. Lin et al. (2014) proposed a system dynamics model to tackle bullwhip effects in a hybrid supply chain of an elevator manufacturing company. They analysed the variations in the service and product flow and proposed several performance metrics. It was found that the bullwhip effect of hybrid supply chain can be mitigated by adjusting the service capacity and using this adjustment in the inventory replenishment framework. Other studies, in terms of solution framework development have been also reviewed; for instance, Shukla and Senevi (2016) proposed a multi agent framework, which used fuzzy rough sets to optimise dynamic SC configuration decisions. Singh et al (2015) proposed a cloud computing framework for assessing the carbon footprint in a food supply chain. Tyagi et al $(2013,2011)$ used non-discrete ant colony optimisation and fuzzy goal programming model for the product development stages in a supply chain. Verma et al (2014) proposed a model for optimising capacity-planning problem in a multi plant SC problem. 
It often happens that the SC participants opts either slow-transportation/fast-transportation or both/multiple transportation modes to maximize their profit/customer-satisfaction as per the market demand changes. Participant's individual decision might be optimized approach for their own benefits, but induces a risk prone situation of bullwhip effect stimulation. Information sharing contributes appreciable role in alleviation of bullwhip effect possibilities. However, implementation of an optimized control over inventory flow has always been a lucrative task. But, when we refer to a SC scenario, where information sharing is restricted and multiple modes of transportation is available between the participants, ensuring optimal control over inventory flow becomes more complex. In this regard, fixed order-up-to policy has been studied by many researchers under the view of information sharing and lead-time variation influences, but most of the discussions are limited to the one transportation mode with variable lead-time considerations only. Therefore, it is desirable to frame a policy, which is easily implementable and can facilitate optimal control over inventory flow, even considering availability of multiple transportation modes. From a theoretical point of view, this research is an effort towards extending fixed orderup-to policy to harness the effective utilization of multiple transportation modes, and to mitigate bullwhip effect.

Our paper proposes multiple order-up-to policy based inventory replenishment scheme to facilitate a centralized control over the SC process to deal with periodic replenishment issues. This employs an optimal order-up-to level(s) policy where replenishment decisions at each stage of the SC are tracked by allotted order-up-to levels, thereby reducing the need for demand information sharing. Our approach considers various transportation facilities between the SC participants in the decision making process for replenishment quantities to reduce total SC costs, which has been neglected by earlier studies. This paper presents a mathematical model for defining optimal multiple order-up-to levels by the SC participants. In order to find an appropriate optimal order-up-to level(s), the proposed model aims to maximize total profits, satisfy customer demand and minimize total costs (i.e., transportation costs, back order/penalty costs). In doing so, the proposed multiple order-up-to levels based policy facilitates a stringent control over the SC pipeline inventory, ensures high satisfaction level of customer demand and enables timely utilization of available transportation facilities. The paper also demonstrates the implementation aspects of the BFA (Bacterial Foraging Algorithm) as a means to determine the optimal multiple order-up-to level(s). The replenishment operation and dynamics of the SC are validated on several data sets including statistical validation using Percentage Heuristic Gap and two-way ANOVA analysis. 


\section{Proposed multiple order-up-to policy and its mathematical formulation}

The multiple order-up-to policy concerns with the replenishment scenario where the stock levels are periodically reviewed and an amount of the item is ordered to return stock levels to the targeted level (order-up-to level). Traditionally, if the periodically reviewed inventory model is not regulated through any order up-to level approach, the average inventory/maximum inventory level at the participants does not remain consistent. This is because inventory level varies significantly at each review cycle as the order quantity depends upon inventory replenishment policy, historical data, current inventory level and forecasted demand. Therefore, sustainability cannot be achieved with optimal cost over a long period. This research investigates the optimal multiple order-up-to levels based replenishment policy for multi-stage sustainable supply chain over a long period. A replenishment policy is developed by assigning optimal multiple order-upto level(s) for each participant of the multi-stage supply chain. In this paper, a single product multi-echelon serial supply chain is taken into consideration, which consists of a retailer, wholesaler, distributor and manufacturer. The considered supply chain with various flows is depicted in Figure 1. Each member manages their inventory level by placing an optimal order on their upstream member. Under the optimal order-up-to policy, replenishment orders are placed by each member of the supply chain to minimise the overall expected costs(i.e. sum of the replenishment, holding, and backorder costs) of the supply chain.

The proposed scheme is similar to the fixed order-up-to policy approach where replenishment decision "how much to order" are made periodically on the basis of a fixed order-up-to inventory level. Since, the proposed scheme deals with the problem scenario very close to the realistic supply chain scenarios where the multiple transportation modes are used for replenishments. The replenishment scheme is designed as such the complex periodic decision related to the transportation mode and the order quantities can be decided using multiple order-up-to levels.

For a simple problem scenario comprising constant consumption rate, the multiple order-up-to scheme (having two order-up-to levels: one order-up-to level to decide order quantity using fast transportation, other to decide order quantity using slow transportation) is graphically represented comparing with traditional fixed order-up-to level model, a graphical illustration is shown in figure 2. It can be observed that multiple order-up-to policy reduces the gap between maximum inventory and minimum inventory levels consequently provide possibility to reduce average inventory level and to increase demand fulfilment (see Fig 2).

$<$ Insert Figure 1 here $>$ 
$<$ Insert Figure 2 here $>$

Suppose $n$ types of transportation facilities replenish the demand of $k^{\text {th }}$ stage member of multistage supply chain. The replenishment lead time of these transportation facilities are $L_{1, k}, L_{2, k}, \ldots \ldots$ $L_{n, k}$, respectively. All members place their order periodically at the beginning of the period. At time period $t$, the member ' $k$ ' places an order of size $Y_{l, k, t}, Y_{2, k, t}, Y_{3, k, t}, \ldots . Y_{n, k, t}$ by using available ' $n$ ' transportation modes respectively. These order sizes depend upon multiple order-up-to levels $\left(\right.$ Finv $_{1, k}$, Finv $_{2, k}, \ldots$ Finv $\left._{n, k}\right)$ and current inventory level.

Each SC participants have multiple order-up-to levels. Number of order-up-to levels is decided based on number of transportation mode available for demand replenishment. If between the two SC participants ' $n$ ' transportation modes are available then ' $n$ ' order-up-to levels will be assigned for order making. For each transportation modes, there is an optimal order-up-to level to decide the replenishment quantity.

There are certain assumptions that are presumed before formulation and investigation of this replenishment policy.

- Within the available transportation modes, priorities to use the transportation modes are well decided before finding optimal order-up-to levels. The inventory replenishment using faster transportation modes are prioritised over the slower modes.

- Retailer is considered as the lowest level member in SC, whose membership number is 1. Other members have higher membership according to their position in SC.

- Lead time of the transportation modes do not vary and these times are represented as integer numbers.

- Unfulfilled orders are not considered for further fulfilment. Cost incurred due to order unfulfillment is also called 'back order cost'.

- Replenishment scheme provides a centralized approach to determine an optimal order-upto levels for all the SC members, thus the ordering cost can be reduced significantly or can be considered zero.

- Always, manufacturer (highest level SC member) has sufficient inventory to fulfil all the demand.

- At any time period $t$, customer demand is uniformly distributed over the time period.

- Any SC participant replenishes the inventories only from immediate higher level participant. 
- The incidents like order placing, order release, shipment arrival, and back order calculation follow a certain sequence/time as shown in the Figure 3. At time period $t$, start and end times are mainly used for these incidents, thus these times are distinguished with specific names such as Period-beginning Span and Period-closing Span respectively.

\section{$<$ Insert Figure 3 here $>$}

Figure 3 illustrates the sequence of the incidents (order placing, order release, shipment goods arrival, back order calculation) which occurs at $k^{\text {th }}$ stage during time period $t$. For implementing this policy, $k^{\text {th }}$ stage member follows the shown incidents in sequence. First three incidents occur in Period-beginning Span and last three incidents occur in Period-closing Span.

$k^{\text {th }}$ stage member follows the incidents given below in sequence.

\section{//At any time period $t / /$}

Incident1: The shipment goods which are scheduled to reach $k^{\text {th }}$ stage member at time period $t$ $\left(\boldsymbol{A} \boldsymbol{Y}_{1, \boldsymbol{k}, t} / \boldsymbol{A} \boldsymbol{Y}_{2, \boldsymbol{k}, t} / \ldots / \boldsymbol{A} \boldsymbol{Y}_{\mathrm{n}, \boldsymbol{k}, t}\right)$, arrive at the start of the period.

Incident2:Initial inventory level $\left(\boldsymbol{I n n}_{\boldsymbol{k}, t}\right)$ at time period $t$ is counted after the arrival of shipment goods.

Incident3: Orders $\left(\boldsymbol{R} \boldsymbol{Y}_{1, \boldsymbol{k}, t} / \boldsymbol{R} \boldsymbol{Y}_{2, \boldsymbol{k}, t} / \ldots / \boldsymbol{R} \boldsymbol{Y}_{\mathbf{n}, \boldsymbol{k}, t}\right)$ are dispatched for $(k-1)^{\text {th }}$ stage member.

Incident4: New orders $\left(\boldsymbol{Y}_{1, k, t} / \boldsymbol{Y}_{2, k, t} / \ldots / \boldsymbol{Y}_{\mathrm{n}, \boldsymbol{k}, t}\right)$ are placed to $(k+1)^{\text {th }}$ stage member.

Incident5: Final inventory level $\left(\boldsymbol{L} \boldsymbol{i n v} \boldsymbol{v}_{k, t}\right)$ is estimated.

Incident6: Estimation of total unfulfilled orders $\left(\boldsymbol{B i n v}_{k, t}\right)$.

\section{//Increase the period number by 1 , and again iterated from Incident1//}

The mathematical model to determine optimal multiple order-up-to levels for each member of the supply chain is described below:

The list of notations used in the mathematical formulation of the problem is described as follows:

\begin{tabular}{|c|c|}
\hline$L_{i, k}$ & $\begin{array}{l}\text { Replenishment lead time of } i^{\text {th }} \text { type transportation facility between stage } k+1 \\
\text { to } k \text {, where } i=1,2,3 \ldots \mathrm{n}\end{array}$ \\
\hline$H C$ & Per unit holding cost \\
\hline$B C$ & Per unit back order cost \\
\hline$T C_{i}$ & Per unit transportation cost using $i^{\text {th }}$ transportation facility \\
\hline$S P$ & Per unit selling cost of the product \\
\hline$F c d_{t}$ & Consumer demand fulfilled by the retailer at time period $t$ \\
\hline $\operatorname{Linv}_{k, t}$ & $\begin{array}{l}\text { Inventory level of } k^{\text {th }} \text { stage at the end of time period } t \text { (shipment goods are not } \\
\text { added) }\end{array}$ \\
\hline $\operatorname{Iin} v_{k, t}$ & Inventory level of stage $k$ at the starting of time period $t$ (after arrival of \\
\hline
\end{tabular}




\begin{tabular}{|c|c|}
\hline & shipment goods) \\
\hline$D_{k, t}$ & Demand realized by $k^{\text {th }}$ stage participant during time period $t$ \\
\hline$D_{1, t}$ & Customer demand at time period $t$ (Demand realized by the retailer) \\
\hline $\operatorname{Finv}_{i, k}$ & $\begin{array}{l}\text { Fixed order-up-to inventory level of stage } k \text { that is used to decide order } \\
\text { quantity using } i \text { th transportation (if the stage } k \text { has ' } n \text { ' types of transportation } \\
\text { facilities then ' } n \text { ' order-up-to levels will be decided) }\end{array}$ \\
\hline$Y_{i, k, t}$ & $\begin{array}{l}\text { Order made by } k^{\text {th }} \text { stage member at time period } t \text { using } i^{\text {th }} \text { type transportation } \\
\text { (order is made at the end of the time period) }\end{array}$ \\
\hline$R Y_{i, k, t}$ & $\begin{array}{l}\text { Inventory released by } k^{\text {th }} \text { stage member to }(k-1)^{\text {th }} \text { stage member at the } \\
\text { beginning of period } t \text { using } i^{\text {th }} \text { transportation facility }\end{array}$ \\
\hline$B i n v_{k, t}$ & Back order inventory of the stage $k$ at time period $t$ \\
\hline $\operatorname{Cinv}_{k, t}$ & $\begin{array}{l}\text { Total inventory transported from the } k^{\text {th }} \text { stage member to }(k-1)^{\text {th }} \text { stage member } \\
\text { at time period } t \text { by all transportation facilities }\end{array}$ \\
\hline $\mathrm{AY}_{i, k, t}$ & $\begin{array}{l}\text { Stage } k \text { received the inventory using } i^{t h} \text { transportation at the end of time } \\
\text { period } t\end{array}$ \\
\hline
\end{tabular}

The model presents a periodic replenishment policy wherein the order is placed at the beginning of the period. At any time period $t$, quantity of product replenished utilizing the available (n type of transportation) transportation is determined using Eqns. 1-3. The Eq. 1 represents the order size placed by $k^{\text {th }}$ stage of the SC in time period $t$ for $l^{\text {st }}$ transportation option. The replenishment quantity for $i^{\text {th }}$ transportation type at $k^{\text {th }}$ stage and $t^{\text {th }}$ time period is the difference between fixed order-up-to inventory levels of stage $k u s i n g 1^{\text {st }}$ transportation option $\left(F i n v_{1, k}\right)$ and inventory level of $k^{\text {th }}$ stage at the end of time period $t-1\left(\operatorname{Lin} v_{k, t-1}\right)$. Mathematically,

$Y_{1, k, t}=$ inv $_{1, k}-\operatorname{Linv}_{k, t-1}$

However, in case of subsequent $i \in(2,3, \ldots, \mathrm{n})$ transport options, the replenishment quantity $\left(Y_{i, k, t}\right)$ is estimated by the subtraction of fixed order-up-to level belong to the particular transportation mode $\left(F i n v_{i, k}\right)$ to the sum of $\operatorname{Lin} v_{k, t-1}$ and total inventory ordered using upper priority transportation modes. Therefore,

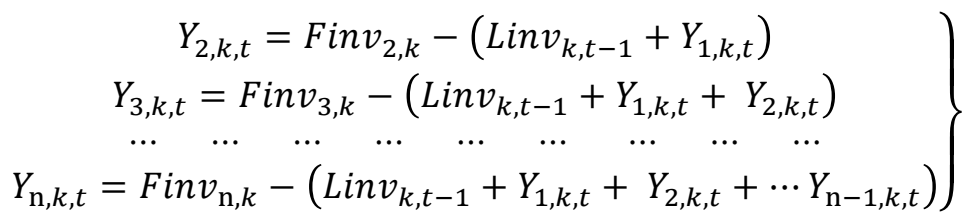

The total inventory that is released using all the available transportation modes from the stage $k$ toward stage $k-1$ at time period $t$ is denoted by $\operatorname{Cinv}_{k, t}$. Mathematically,

$$
\operatorname{Cinv}_{k, t}=\sum_{i=1}^{\mathrm{n}} R Y_{i, k, t} \quad \forall k \in(2,3, \ldots, \mathrm{m}), t \in(1,2,3, \ldots, \mathrm{T})
$$


The relationship replenished quantities and the demanded quantities at each stage using different transportation facilities are given by:

$R Y_{i, k+1, t} \leq Y_{i, k, t} \quad \forall i \in(1,2,3 \ldots, \mathrm{n}), k \in(2,3 \ldots, \mathrm{m}-1), t \in(1,2,3, \ldots, \mathrm{T})$

The initial inventory level of $k^{\text {th }}$ stage member is determined as:

$\operatorname{Iinv}_{k+1, t}=\operatorname{Linv}_{k, t-1}+\delta_{k, t}$

$\delta_{k, t}=\sum_{i=1}^{\mathrm{n}} A Y_{n, k, t} \quad \forall i \in(1,2,3, \ldots, \mathrm{n}), k \in(1,2,3 \ldots, \mathrm{m}-1), t \in(1,2,3, \ldots, \mathrm{T})$

The demand realised by $k+1$ stage member can be evaluated by:

$D_{k+1, t}=\sum_{i=1}^{\mathrm{n}} Y_{1, k, t} \quad \forall i \in(1,2,3 \ldots, \mathrm{n}), k \in(2,3 \ldots, \mathrm{m}-1), t \in(1,2,3, \ldots, \mathrm{T})$

The back order quantity at the $k^{\text {th }}$ stage at time period $t$ can be determined by Eq.(8).

Binv $_{k, t}=\left\{\begin{array}{cc}\theta_{k, t} & \text { if } \theta_{k, t}>0 \\ 0 & \text { otherwise }\end{array}\right.$

$\theta_{k, t}=D_{k, t}-\operatorname{Iinv}_{k, t} \forall k \in(1,2,3 \ldots, \mathrm{m}), t \in(1,2,3, \ldots, \mathrm{T})$

The inventory level of $k^{\text {th }}$ stage at the end of period $t$ is determined as:

$\operatorname{Lin} v_{k, t}=\left\{\begin{array}{cr}\operatorname{Iin} v_{k, t}-D_{k, t} & \text { if } \operatorname{Iin}_{k, t} \geq D_{k, t} \\ 0 & \text { Otherwise }\end{array}\right.$

The quantity of fulfilled customer demand in any period of time $t$ can be defined as follows-

$F c d_{t}=\left\{\begin{array}{cc}D_{1, t} & \text { if }\left(\operatorname{Iinv}_{1, t}-D_{1, t}\right)>0 \\ \operatorname{Iinv}_{1, t} & \text { otherwise }\end{array} \forall k \in(1,2,3 \ldots, \mathrm{m}), t \in(1,2,3, \ldots, \mathrm{T})\right.$

Subjected to following constraints:

$$
\begin{array}{lc}
L_{i, k}<L_{i+1, k} \forall i \in(1,2,3, \ldots, \mathrm{n}-1), k \in(1,2,3, \ldots, \mathrm{m}) \\
\text { Finv }_{i, k} \geq 0 & \forall i \in(1,2,3, \ldots, \mathrm{n}), k \in(1,2,3, \ldots, \mathrm{m}) \\
Y_{i, k, t} \geq 0 & \forall i \in(1,2,3, \ldots, \mathrm{n}), k \in(1,2,3, \ldots, \mathrm{m}), t \in(1,2,3, \ldots, \mathrm{T}) \\
\text { Linv }_{k, t} \geq 0 & \forall k \in(1,2,3, \ldots, \mathrm{m}), t \in(1,2,3, \ldots, \mathrm{T})
\end{array}
$$

The total sales cost of the product for entire time period $T$ is:

sales $=\sum_{t=1}^{\mathrm{T}}\left(S P \cdot F c d_{t}\right)$

The total inventory holding cost for $m$ players in SC and in $T$ time periods is determined as:

total holding cost $=\sum_{t=1}^{\mathrm{T}} \sum_{k=1}^{\mathrm{m}-1}\left(H C \cdot \operatorname{Linv}_{k, t}\right)$

The back order costs for $m$ players in SC and in $T$ time periods can be determined as:

total back order cost $=\sum_{t=1}^{\mathrm{T}} \sum_{k=1}^{\mathrm{m}-1}\left(B C \cdot \operatorname{Binv}_{k, t}\right)$

Finally, the transportation costs for $\mathrm{m}$ players in $\mathrm{SC}$, in $\mathrm{T}$ time periods, and $\mathrm{n}$ transportation facilities can be determined as:

total transportation costs $=\sum_{t=1}^{\mathrm{T}} \sum_{k=1}^{\mathrm{m}-1} \sum_{i=1}^{\mathrm{n}}\left(T C_{i} \cdot Y_{i, k, t}\right)$

Total accumulated profit for entire $\mathrm{SC}$ of $\mathrm{m}$ players, after running it for ' $\mathrm{T}$ ' periods/weeks is: 


$$
\begin{aligned}
\text { Total Profit }= & (\text { sales }- \text { total holding cost }- \text { total back order cost } \\
\text { Total Profit }= & \sum_{t=1}^{\mathrm{T}}\left(S P \cdot F c d_{t}\right) \\
& -\sum_{t=1}^{\mathrm{T}} \sum_{k=1}^{\mathrm{m}-1}\left(H C \cdot \operatorname{Linv}_{k, t}\right)-\sum_{t=1}^{\mathrm{T}} \sum_{k=1}^{\mathrm{m}-1}\left(B C \cdot B \operatorname{Bin} v_{k, t}\right)-\sum_{t=1}^{\mathrm{T}} \sum_{k=1}^{\mathrm{m}-1} \sum_{i=1}^{\mathrm{n}}\left(T C_{i} \cdot Y_{i, k, t}\right)
\end{aligned}
$$

Therefore, the optimal order-up-to levels are determined by maximizing the total acquired profit of the SC for number of periods. In this article, the Bacterial Foraging Algorithm is used to determine the optimal multiple order-up-to levels for maximizing profit over a long period.

In a situation where supply chain entities do not share the type and status of their inventory system with other entities, this creates the bullwhip effect and difficulty in the control and forecasting of inventories. To overcome these difficulties, aforementioned mathematical model has been developed and its advantages can be demonstrated over the four causes of bullwhip effect: demand signal processing, rationing game, price variation and order batching.

Demand signal processing: Improper demand signal processing is known as one of the major causes of bullwhip effect. In order to reduce the effect, most literature recommends a continuous information sharing based model and effective utilization of forecasting techniques (Nienhaus et al, 2006). However, under the assumed scenario of the SC where the information sharing between the members are not available, the SC participants usually rely on forecasting methods. There are several forecasting techniques (moving average, exponential soothing forecasting etc.) to realize customer demand trends. However, existing forecasting methods are unable to successfully trace on- time demand variation.

Thus, the information transferred in the form of an order tends to be distorted and can misguide upstream members in their inventory and production decisions. Sometimes this distorted information can cause amplification in the SC pipeline inventory level. However, the proposed policy employs a centrally governed (governed by manufacturer) replenishment scheme, where all participants work as a team and utilizes an optimal order-up-to level policy. In order to establish a controlled flow, the policy assigns an optimum desired inventory level for every participant to maintain stringent control. It provides guidance for ordering the product at each 
stage of the supply chain and ensures the coherency of material flow patterns among different stages.

Rationing and storage gaming: The effect of rationing game generally takes place in a situation when the product demand exceeds supply. To deal with the shortage, the manufacturer follows a rationing scheme and distributes the limited production in proportion to the orders of the downstream members. Downstream entities respond to this by increasing their demand, which leads the distortions in the supply chain. The situation is exacerbated when consumers adopt hoarding behaviour in response to actual or perceived scarcity. In conditions of scarcity, some consumers exaggerate their orders to ensure finding sufficient quantities of product. Owing to this high fluctuation of demand from consumers, it becomes difficult to trace the actual demand. The model presented in this paper addresses these problems. The order created by the member is decided on the basis of remained inventory in stock and an assigned optimal order-up-to level of inventory. Across the SC, ordering decisions are taken in accordance with a network-wide policy, instead of in reaction to oncoming demands. Thereby, it reduces the effect of customer demand fluctuation over the whole SC.

Price variation: Customer demand increases when the product is available at low prices. Having a special promotion scheme for the product such as price discounts, coupons, quantity discount, and rebates prompts customers to buy the product in large quantities that creates high fluctuation in demand levels. Ideally, participants are usually ready to meet increased demand before any special promotion scheme. However, the proposed model encompasses a time variable to assign a new order-up-to levels to cope up the expected demand due to a promotion scheme.

Order batching: Order batching refers to a situation where demand is created in a large amount at one period followed by a period of low demand. If a supplier serves several customers, there is a possibility that many customers would create demand in the same period. In this situation supplier faces a highly erratic stream of orders which leads to demand spike in the same period followed by diminished demand for a subsequent period. The main advantages of the proposed continuous replenishment program are: it helps to minimize the inventory in supply line; it reduces the possibility of rationing storage gaming; and finally, it reduces the intensity of storage variation at the intermediate stages. Further, the proposed approach also helps to reduce the order batching effect by small sized shipments using appropriate transportation modes. 


\section{Bacterial Foraging Algorithm (BFA)}

Determination of optimal multiple order-up-to levels is computationally complex optimization (NP-hard) problem. Complexity of the problem increases exponentially as the number of supply chain members or the number of transportation modes increases. Applications of deterministic methods become impractical in such computationally complex problems. In last decade, metaheuristic approaches have emerged to be a powerful method to solve the NP hard problem in near real time (Tiwari et. al. 2006). In our article a meta-heuristic algorithm, the BFA, is employed to obtain optimal multiple order-up-to levels for each SC participant in multi-stage supply chain network.

BFA is inspired by social foraging behaviour of E-colibacterium (Passino 2002). In foraging theory, a bacterium searches for nutrients to maximize the energy intake per unit of time. Each bacterium has an underlying sensing ability which allows a bacterium to signal others in the group, and this facilitates an efficient swarming tendency towards the rich nutrient hub. During the search process the bacterium population performs several activities, which include chemotactic, swarming, reproduction, elimination and dispersion actions, as discussed below.

Chemotactic step: In this step swimming and tumbling action is performed. Swimming action facilitates the search process by exploring the new area, whereas tumbling actions help to reach the optimal solution in the immediate vicinity or neighbourhood. Suppose $\Phi^{\mathrm{i}}(a, b, c)$ represents the $\mathrm{i}^{\text {th }}$ bacterium at $a^{\text {th }}$ chemotactic, $b^{\text {th }}$ reproductive and $c^{\text {th }}$ elimination-dispersal step. The size of step taken in any random direction is taken to be $C(\mathrm{i})$. The movement of the bacterium is modelled as:

$$
\Phi^{\mathrm{i}}(a+1, b, c)=\Phi^{\mathrm{i}}(a, b, c)+C(\mathrm{i}) \frac{\Delta(\mathrm{i})}{\sqrt{\Delta^{T}(\mathrm{i}) \Delta(\mathrm{i})}}
$$

where, $\Delta(\mathrm{i})$ is the random direction vector with its elements in $[-1,1]$.

The number of chemotactic steps is represented as $N_{c}$ and number of number of swimming steps is represented as $N_{s}$.

Swarming step: In swarming step, a subgroup of bacteria can aggregate themselves into groups and move as a concentric pattern of swarms. During these steps, the cell-to-cell signalling ability (attraction and repulsion characteristics) of bacteria helps them to search for a better nutrient 
place in less time. This group behaviour gives rise to the cell-to-cell signalling $\left(\omega_{c c}(\cdot)\right)$, which is represented as:

$$
\begin{gathered}
\omega_{c c}(\Phi, \mathrm{P}(\mathrm{a}, \mathrm{b}, \mathrm{c}))=\sum_{\mathrm{i}=1}^{S} \omega_{c c}\left(\Phi, \Phi^{\mathrm{i}}(\mathrm{a}, \mathrm{b}, \mathrm{c})\right) \\
=\sum_{\mathrm{i}=1}^{S}-d_{\text {attract }} \cdot e^{\left[-v_{\text {attract }} \sum_{m=1}^{p}\left(\omega_{m}-\omega_{m}^{\mathrm{i}}\right)^{2}\right]}+\sum_{\mathrm{i}=1}^{S}-d_{\text {repellant }} \cdot e^{\left[-v_{\text {repellant }} \sum_{m=1}^{p}\left(\omega_{m}-\omega_{m}^{\mathrm{i}}\right)^{2}\right]}
\end{gathered}
$$

where, $S$ is the total number of bacterium, $\omega_{c c}(\Phi, \mathrm{P}(\mathrm{a}, \mathrm{b}, \mathrm{c}))$ is the value to be added to the actual objective function $\omega(\Phi), d_{\text {attract }}, d_{\text {repellant }}, v_{\text {attract }}$, $v_{\text {repellant }}$ are some of the coefficients that are defined by the user, and $p$ is the number of variables to be optimised. Thus, $\Phi=\left[\begin{array}{lll}\Phi_{1} & \Phi_{2} & \ldots\end{array} \Phi_{p}\right]^{T}$

The maximisation of objective function, i.e., total profit (Eqn. 20), is represented as $\omega(\Phi)$ at position $\Phi$. Thus $\omega(\mathrm{i}, a, b, c)$ denotes the health of $\mathrm{i}^{\text {th }}$ bacterium at location $\Phi^{\mathrm{i}}(a, b, c)$.

Reproduction step: the reproduction process is the process of generation of new bacteria and elimination of old ones. The bacteria involved in the reproduction process have better nutrient accumulation. Moreover, some least accumulated bacteria disappear and the newly reproduced bacteria occupy empty positions. The number of reproduction steps is represented as $N_{r e}$.

Elimination and dispersal step: This step takes place after the completion of reproduction step. Some bacteria get eliminated and a new, randomly located bacterium gets the position in the population. These eliminations of bacteria occur on the basis of a defined probability. From the optimization point of view, if an elimination of a bacterium takes place, it simply disperses one to a random location in the search space. In the algorithm, $N_{e d}$ represents the number of elimination and dispersal steps and $p_{e d}$ represents the elimination and dispersal probability.

The pseudo-code bacterial foraging algorithm is given below.

\section{Pseudo-code}

Parameter initialization

Initialization of bacterium population

Computew $\left(\Phi^{\mathrm{i}}\right) \forall \mathrm{i}$

for $\left(c=1\right.$ to $\left.N_{e d}\right)$

for $\left(b=1\right.$ to $\left.N_{r e}\right)$

for $\left(a=1\right.$ to $\left.N_{c}\right)$

$$
\text { for }(\mathrm{i}=1 \text { to } S)
$$


//Take a chemotactic step for $\mathrm{i}^{\text {th }}$ bacterium:

Compute

$$
\omega(\mathrm{i}, a, b, c)=\omega(\mathrm{i}, a, b, c)+\omega_{c c}\left(\Phi^{\mathrm{i}}(a, b, c), P(a, b, c)\right)
$$

$/ /$ fitness function for $i^{\text {th }}$ bacterium using Eqn. 20

I/Tumbling Step

Generate a random direction vector $\Delta(i)$

I/Moving Step

Compute move operation using Eqn. 21

Compute $\omega(\mathrm{i}, a+1, b, c)$ as

$$
\omega(\mathrm{i}, a, b, c)=\omega(\mathrm{i}, a, b, c)+\omega_{c c}\left(\Phi^{\mathrm{i}}(a+1, b, c), P(a+1, b, c)\right)
$$

\section{I/Swimming Step}

Let $z=1$

while $\left(z<N_{S}\right)$

do

$\mathbf{I f}\left(\omega(\mathrm{i}, a+1, b, c)>\omega_{\text {last }}\right)$

$\omega_{\text {last }}=\omega(\mathrm{i}, a+1, b, c)$ and

$$
\Phi^{\mathrm{i}}(a+1, b, c)=\Phi^{\mathrm{i}}(a, b, c)+C(\mathrm{i}) \frac{\Delta(\mathrm{i})}{\sqrt{\Delta^{T}(\mathrm{i}) \Delta(\mathrm{i})}}
$$

//use $\Phi^{\mathrm{i}}(a+1, b, c)$ to compute the new $\omega(\mathrm{i}, a+1, b, c)$

$z=z+1$;

else

$z=N_{s}$

end-do

//goto next bacterium processing $(\mathrm{i}+1)$

end// all bacterium are processed

//goto next chemotactic step $(a+1)$

end// end of chemotactic step

//perform reproduction step

Evaluate the value of $\omega_{\text {health }}^{\mathrm{i}}=\sum_{a=1}^{N_{c}+1} \omega(\mathrm{i}, a, b, c)$

Half of the bacteria with smallest $\omega_{\text {health }}^{\mathrm{i}}$ die and another halfbacteria with the best values

split and reproduced bacterium occupy the place of dead bacterium.

//goto the next Reproduction step $(b+1)$

end// end of reproduction step

Ilelimination and dispersal loop

for $(\mathrm{i}=1$ to $S)$

Randomly generate probability

if (generated probability $<p_{e d}$ )

Eliminate the bacterium

Generate a bacterium at a random location

end

end// end of elimination and dispersal loop

$/ /$ goto the next elimination and dispersal step $(c+1)$

end// end of elimination and dispersal step 


\section{Implementation of BFA}

An example of multi-stage supply chain has been numerically simulated to demonstrate the execution process of BFA. In this example, each supply chain member has two transportation facilities. Due to having two transportation opportunities, it is required to assign two optimal order-up-to levels for the participants.

Model information used to numerically simulate and obtain optimal order-up-to levels were:

- Input variables: $<$ Finv $_{1,1}$, Finv $_{1,2}$, Finv $_{1,3}$, Finv $_{2,1}$, Finv $_{2,2}$, Finv $_{2,3}>$ (each SC participant has two transportation modes for replenishing the inventory; it is the same supply chain network as shown in figure $1 ; \mathrm{n}=2, \mathrm{~m}=4$ )

- Objective: profit maximization (see Eq.20)

- Range of Input variables:

$0 \leq$ Finv $_{1,1} \leq 50 ; \quad 0 \leq$ Finv $_{1,2} \leq 50 ; \quad 0 \leq$ Finv $_{1,3} \leq 50 ; \quad 0 \leq$ Finv $_{2,1} \leq 50 ; \quad 0 \leq$ Finv $_{2,2} \leq 50 ; 0 \leq$ Finv $_{2,3} \leq 50$

- Associated costs: selling price of the product $=\$ 3.0$ per unit; back order cost $=\$ 1.50$ per unit; holding cost $=\$ 0.25$ per unit per period

- Number of periods: $\mathrm{T}=100$ periods

- Initial inventory levels at $\mathbf{1}^{\text {st }}$ period:Linv L $_{1,0}=15$ unit; Linv Li, $_{2,0}=15$ unit; Linv L $_{3,0}=15$ unit; $A Y_{1,1,1}=15$ unit; $A Y_{2,1,1}=0$ unit; $A Y_{1,2,1}=15$ unit; $A Y_{2,2,1}=0$ unit; $A Y_{1,3,1}=15$ unit; $A Y_{2,3,1}=$ Ounit. Thus (retailer) $\operatorname{Iinv}_{1,1}=30$ unit, (warehouse) $\operatorname{Iin}_{2,1}=30$ unit, (distributor) Iinv $_{3,1}=30$ unit

- Consumer demands of past 100 periods: as shown in Table 4

To determine the optimal order-up-to levels for each participant (retailers, warehouses, and distributors) the bacterium can be represented as $<13,14,19,20,25,32>$. In this string, the first three numbers represent the first order-up-to level and last three numbers identify the second order-up-to level of retailer, warehouse, and distributor respectively. For each member, replenishment amount equal to the difference between the first order-up-to level and current inventory is ordered from their immediate upstream member using the fastest available transportation facility. A further quantity of replenishment is ordered on the basis of the second order-up-to level, current inventory and received inventory using the slower transportation mode. Suppose, at the end of period ' $t-1$ ' each of the retailer, warehouse and distributor has remained inventory 2, 4 and 1 units respectively and their optimal order-up-to levels are $<13,14,19,20$, $25,32>$. According to the policy, in period $t$, retailer orders a replenishment of 11 (13-2) units by using fast transportation and 7 (20-13) units by using the slower transportation facility. Similarly, the warehouse and distributor replenish, respectively, 10 and 11 units and 18 and 13 units by utilizing the first and second transportation modes. Further, different sets of order-up-to levels are searched by performing simulation for a number of periods utilizing historical customer demand 
data. For maximization of total accumulated profit of the SC, the algorithm serves to determine the optimal order-up-to level/levels for each participant. The complexity in the search process arises in the first instance because of the wide range of order-up-to levels (integer values $[0,50]$ ). The problem becomes more complex when there is a need to determine order-up-to levels for a long period of time.

To solve such complex optimization problem, BFA is proposed to find the optimal order-up-to level(s) to achieve maximum profit. BFA is relatively new nature inspired optimization algorithm, a promising method for distributed non-gradient search.BFA is known to be robust with respect to the size and non-linearity of the optimisation problem. It also has benefits in terms of less computational burden, global convergence and less computational time requirement. The problem illustrated here maximizes the total profitability of the replenishment scheme where the variation in multiple order-up-to levels directly influence the sort-term objectives (customer satisfaction \& stringent control over pipe-line inventory in the supply chain) as well as the long term (100 periods) overall profitability of the supply chain. In the mathematical model, short-term objectives, long-term goal and bullwhip effects are mutually influenced by each other. It is imperative that the BFA searches the solution space with a slow bacterial move. The swarming ability of the bacterium via attractant and repellent signals simultaneously works for higher proximity towards global optimum, by avoiding the possibility of entrapment into the local optima.

The following configuration is used to run the BFA algorithm:

Bacterium string $(\Phi)=<$ Finv $_{1,1}$, Finv $_{1,2}$, Finv $_{1,3}$, Finv $_{2,1}$, Finv $_{2,2}$, Finv $_{2,3}>$;

Bacterium nutrient concentration $(\omega(\Phi))=$ Total profit over the 100 period of time (objective function as in Eq.20);

Bacterium population $(S)=20$; number of chemotectic iteration $\left(N_{c}\right)=50$; number of swarming iteration $\left(N_{s}\right)=4$; number of reproduction iterations $N_{r e}=4$; number of elimination and dispersion iteration $\left(N_{e d}\right)$ depends upon global convergence characteristics; $P_{e d}=0.46, C(i)=2.1, \mathrm{~d}_{\text {attract }}=0.9$, $\mathrm{d}_{\text {repellant }}=0.9, \mathrm{v}_{\text {attract }}=1.2, \mathrm{v}_{\text {repellant }}=1.2$.

To demonstrate the effectiveness of the proposed algorithm, it is compared against the Genetic Algorithm (GA). The performance (searching of best fitness value) of both algorithms has been plotted against total number of fitness evaluation (Figure 4).Before the optimization, both algorithm's (GA and BFA) parameters were tuned with proper care and experimental iteration support. In all three problem scenarios, BFA acquired fitness value (Total profit) moves faster toward the optimum (maximum) point than the GA acquired fitness value. BFA finds the best 
solution in less number of iterations. Moreover, the final best solutions obtained by BFA for all three problem scenarios are superior than the GA obtained solutions. Optimization experiments were performed many times to evaluate the performances of BFA and GA, results were quite similar as shown in the Figure 4. It is clear that BFA algorithm outperforms GA algorithm.

$<$ Insert Figure 4 here $>$

\section{Results and discussion}

In this section, we summarize the numerical investigations performed to validate the effectiveness of the proposed method. A single product, practical supply chain problem is considered, where the manufacturer has information on past consumer demand data in form of its mean and variance. The manufacturer uses a policy-based replenishment program to maintain a continuous flow of product across the supply chain. There are two types of transportation facilities that the participants can utilize. In order to carry out the experiments, several stochastic customer demand sets (randomly, normal distribution with mean=30 and variance=5) have been generated and utilized to simulate three types of transportation scenarios.

Scenario 1: The SC participants utilize slow transportation for their replenishment programs Scenario 2: The SC participants utilize fast transportation for their replenishment programs

Scenario 3: Both transportation opportunities are utilized for the replenishment programs

The analysis of these three scenarios aims to select the cost-effective transportation method. To perform the simulations, the algorithm has been coded in $\mathrm{C}++$ and was run on an Intel i5 CPU at 2.13 GHz. For all experiments, the applied costs are as follows: per unit selling price of the product $=\$ 3.0$; back order cost $=\$ 1.50$ per piece of product (this cost is assumed as a penalty cost when demand is unsatisfied); finally, holding cost $=\$ 0.25$ per unit per period, (it can be assumed as a penalty cost for extra inventory that remains at the end of the period). The replenishment lead-time of the transportation modes are one and two periods, for fast and slow transportation respectively. Similarly, per unit transportation costs are $\$ 0.4$ and $\$ 0.2$, respectively. Aforementioned problem parameters are generated by following the general guidelines available in the literature and combining them in the preliminary experiments.

First two problem scenarios (where only one transportation modes are available) are similar to the fixed order-up-to policy based replenishment having no variation in lead time (Chen et al., 2000a). Simchi-levi et al. (2008) discussed several two stage SC problems dealing with various distribution of customer demand. Similar problem scenarios, having single transportation mode is also investigated by O'Donnell et al. (2006). Making comparison between first and second 
scenario results gives insight that only changing the mode of transportation does not bring significant improvement in profit outcomes (refer the results shown in Table 2 and Table 3). Third problem scenario has been introduced to represent the use/effectiveness of multiple mode transportation over the one mode transportation use. The profit outcome by use of multiple transportation modes increases significantly, have been justified by all the conducted experiments, results are shown in Table 4. It is worth to notice that the incurred costs are kept same in all the problem scenarios. As well as, it is ensured that in each experiment, customer demand is generated for 100 periods following the normal distribution pattern, and the same customer demand (100 periods) is deployed for all three problem scenarios one-by-one. So that, the result outcomes from the scenarios can be evaluated at common platform of incurred costs \& customer demand, and valuable inferences can be drawn. Moreover, the benefits and the limitations of multiple transportation modes replenishment over the single transportation replenishment can be evaluated comparing with scenario 1 and scenario 2 results in each single experiment separately.

Scenario 1: The SC participants utilize slow transportation for their replenishment programs

For the slow transportation scenario, the test is performed twenty times for different randomly generated customer demands. For the experiments it is assumed that both the lead time and transportation cost are same for all participants. In each experiment, optimal order-up-to levels are determined to maximize the profit by running the SC for 100 periods. The experiments simulate the replenishment program, where the participant utilizes slow transportation and continuously raises their demand at the start of the period. The results and performance have been tabulated (Table 1) in the form of acquired profits and associated optimal order-up-to level for participants (Retailer, Warehouse and Distributor).

$<$ Insert Table 1 here $>$

Scenario 2: The SC participants utilize fast transportation option for their replenishment programs

Similar to the above scenario, experiments have been further performed where participants use fast transportation option. In this scenario, transportation takes less time (one period) to replenish the product. However, the transportation cost is double in comparison to the slow one. The experiments present the combined effect of the diminution of lead time and the increment of 
transportation cost over the performance of long run (100 periods) supply chain and acquired profit. The results of experiments are shown in Table 2. By comparing the results of scenario 1 and scenario 2, we can conclude that the utilization of fast transportation is more effective than the slow transportation to increase overall profit.

$<$ Insert Table 2 here $>$

Scenario 3: Both transportation opportunities are utilized for the replenishment programs

In this case, the experiments test supply chain responsiveness, when both available transportation methods are used to facilitate the continuous flow of product. Similar to the above scenarios, all sets of generated customer demand data are tested. The results (Table 3) show that the acquired profit in this case has been significantly increased. The outcome of the experiments represents dominance of the transportation scenario where both transportation methods are utilized. The partial use of both transportations plays a significant role in minimizing the transportation cost as well as in enhancing the continuity of replenishment. Suppose the result of an experiment for which the obtained optimal order-up-to levels are $<10,10,14,43,31,41>$. In this case, optimal order-up-to levels 10, 10 and 14 provide a limit of inventory for retailer, warehouse and distributor respectively and the fast transportation facility should be utilized. Further, the remaining quantity to reach the second inventory level of 43, 31 and 41 for the same participants respectively, are to be satisfied by the slow transportation method. The optimal order-up-to levels for various customer demand data sets are obtained and investigated to check the robustness and effectiveness of the proposed policy. The results obtained for these experiments are presented in Table 3. By analysing these results, we find that optimal order-up-to levels searched by the BFA algorithm for all sets of customer demand are very close to each other. A probability based selection criterion is used to determine order-up-to levels (see Table 3). According to this selection criterion, we choose the entity which has highest probability to occur frequently (O'Donnell et al. 2006). The probability of the result $<10,10,14,43,31,41>$ for being the best choice is quite high. Therefore, optimal order-up-to level $<10,10,14,43,31,41\rangle$ has been applied over the aforementioned supply chain, where levels 10 and 43 apply to the retailer, levels 10,31 apply to the warehouse and levels 14,41 apply to the distributor. The participants will be bounded to create orders and utilization of transportation in accordance with the assigned orderup-to levels. Supply chain performance has been observed by employing the policy for the 100 periods. From the 100 periods run, some period-wise observation of inventory transactions at the retailer, warehouse, distributor and manufacture stages have been shown in Table 4. Moreover, the responses of supply chain in form of inventory level and customer satisfaction are given by 
the graphical representation in Figure 5 and Figure 6. Optimal order-up-to levels assign a limit for every participant of the supply chain, and participants attempt to achieve this inventory level in each period by creating an order. Thus, the product flow across the supply chain is mainly controlled by the allotted optimal order-up-to levels rather than the forecasted customer demand. The optimal order-up-to level not only limits the ordering quantity at each stage of supply chain but also eliminates the possibility of bullwhip effect by avoiding the direct dependency of order quantity variation with demand fluctuation. If the policy reduces the amplification of ordering quantity, the main challenge is to fulfil the customer demand while maintaining proper inventory level at the different stage. Thus, we have investigated the period-wise performance of an optimal order-up-to level policy in respect of demand satisfaction and inventory level of the different stages. The curve of retailer inventory rarely lies below the customer demand curve (Figure 5). This indicates that back ordering at the retailer stage rarely occurs and that the retailer provides a high degree of customer demand satisfaction (Figure 6). Therefore, we can conclude that the presented optimal order-up-to level policy not only reduces the bullwhip effect by controlling the proper flow of product throughout the supply chain but also facilitates a high degree of customer satisfaction.

\section{$<$ Insert Tables 3 and 4 here $>$ \\ $<$ Insert Figure 5 and 6 here $>$}

To show the robustness of the proposed approach, the BFA algorithm is also tested on large data sets with increased complexity. The larger data set is generated randomly to demonstrate more complex supply chain scenarios. The effectiveness of the algorithm is shown by a new parameter 'Percentage Heuristic Gap $(P H G)$ '. $P H G$ can be mathematically represented as (Huang et al. 2002):

$$
P H G=\frac{(\text { Best upper bound }- \text { Best lower bound })}{\text { Best lower bound }} \times 100
$$

The lower bound is the objective function value obtained by relaxing some of the bounds or constraints pertaining to the problem environment. The upper bound is the value of objective function of any solution that satisfies all the constraints. In the present study, lower bound is calculated by relaxing the penalty cost. According to $P H G$, if the value is very small the near optimal solution of the problem is guaranteed. 
Table 5 shows the parameters values of the randomly generated data sets. The calculated $P H G$ value for various sized data sets is given in Table 6-8.

$<$ Insert Tables 5 - 10 here $>$

To assess the significance of PHG results, a two-way ANOVA without replication was performed. Test was conducted at $95 \%$ confidence level which is highly significant. The results of the ANOVA test are provided in the Tables9-10. From the table, it is clear that the value of $\mathrm{F}$ is greater than $F_{c r i t}$ and simultaneously the $p$-value is also less than significance level $(\alpha=0.05)$. Therefore, the results statistically validate the robustness of the proposed algorithm.

\section{Conclusions}

This paper contributes to the facilitation of a centralised control based supply chain management to effectively deal with the replenishment policies. The proposed approach takes into account the optimal multiple order-up-to policy to reduce the need for information sharing by tracking replenishment decisions at each stage of the SC (using allotted order-up-to levels). Transportation modes and associated costs among SC participants are also considered in making effective decisions on replenishment quantities with a view to reduce overall SC costs. The proposed model maximises total profits along with minimising total SC costs while satisfying customer demand. The resulting solution includeded an optimal order-up-to level(s) for the SC participants. To solve such optimisation model, we have introduced a new emerging BFA which shows greater efficiencies and better solution qualities than its evolutionary algorithm counterpart such as Genetic Algorithm (GA). The results of the proposed approach is tested and validated on several datasets using Percentage Heuristic Gap and two-way ANOVA analysis.

This paper demonstrates a policy based continuous replenishment program where the order quantity at each stage of the supply chain is determined by using an optimal order-up-to level(s). These specifically deal with the SC scenario where the participants are able to acquire local information (can share demand information with immediate down-steam and up-steam members) but they do not have the facility to share information with each member of the SC. The authors have employed the approach over an example of multi-echelon, serial, single product supply chains where the each member of a supply chain has several types of transportation options and they utilize these to reduce the transportation cost and to replenish goods in a timely manner. The research utilizes the BFA approach to determine the optimal order-up-to level(s) and seeks to eliminate the bullwhip effect by avoiding the influence of customer demand fluctuation across the 
SC. Findings show that assigning the optimal order-up-to level approach bounds the order limit, and hence eases the effect of demand variation over the whole SC. In addition, optimal order-upto approach provides a trade-off between inventory level in supply chain and order fulfilments while minimizing the incurred cost. The response of the simulation tests shows that the applied approach can reduce the effect of customer demand variations over the inventory level, ordering quantities and flow of product, at participating stages of the supply chain. Moreover, it eliminates the propagation of distorted customer demand information across the SC. Therefore, this approach significantly reduces the bullwhip effect while establishing a proper product flow into the supply pipeline. Further, the robustness of the proposed algorithm is tested using Percentage Heuristic Gap concept. A two-way ANOVA analysis is also employed to statistically validate the consistency of the proposed BFA algorithm. Research can be further extended to apply and obtain optimal order-up-to level/levels for on-line model, viz. where the model can be updated after certain period, weekly or before launching sale-promotion, changing the price and price discount schemes to improve the responsiveness in the inventory system.

\section{Acknowledgement}

The authors would like to thank the project 'A cross country examination of supply chain barriers on market access for small and medium firms in India and UK' (Ref no: PM130233) funded by British Academy, UK for supporting this research.

\section{References}

Bray, R., Mendelson, H. (2012), Information Transmission and the Bullwhip Effect: An Empirical Investigation, Management Science, 56(5), 860-875.

Cachon, G., Randall, T. and Schmidt, G. (2007), In Search of the Bullwhip Effect, Manufacturing and Service Operation Management, 9(4), 457-479.

Cachon, G.P. (1999), Managing Supply Chain Demand Variability with Scheduled Ordering Policies, Management Science, 45 (6), 843-856.

Cetinkaya, S., Lee, C.Y. (2000), Stock Replenishment and Shipment Scheduling for VendorManaged Inventory Systems, Management Science, 46(2), 217-232.

Chen, F., Drezner, Z., Ryan, J., Simchi-Levi, D. (2000a), Quantifying the bullwhip effect in a simple supply chain: The impact of forecasting, lead times, and information, Management Science, 46(3), 436-443.

Chen, F., Drezner, Z., Ryan, J., Simchi-Levi, D. (2008), The bullwhip effect: managerial insights on the impact of forecasting and information on variability in a supply chain, Quantitative Model for Supply Chain Management, 418-439.

Chen, F., Ryan, J., Simchi-Levi, D. (2000b), The impact of exponential smoothing forecasts on the bullwhip effect. Naval Research Logistics, 47 (4), 271-286. 
Chopra, S., Meindl, P. (2001), Supply Chain Management: Strategy, planning, and Operation. Upper Saddle River, New Jersey. Prentice-Hall, Inc., 33-37.

Croson, R., Donohue, K. (2006), Behavioural Causes of the Bullwhip Effect and the Observed Value of Inventory Information, Management Science, 52(3), 323-336.

Croson, R., Donohue, K., Katok, E., Sterman, J. (2005), Order Instability in Supply Chains: Coordination Risk and the Role of Coordination Stock. MIT. http://web.mit.edu/ jsterman/www/Order Stability 070505.pdf.

De Almeida, M.M.K., Marins, F.A.S., Salgado, A.M.P., Santos, F.C.A., Da Silva, S.L., (2015), Mitigation of the bullwhip effect considering trust and collaboration in supply chain management: a literature review, International Journal of Advanced Manufacturing Technology, 77(1), 495-513.

Dejonckheere, J., Disney, S.M., Lambrecht, M.R., Towill, D.R. (2003), Measuring the Bullwhip effect: A control theoretic approach to analyse forecasting induced Bullwhip in order-up-to policies, European Journal of Operational Research, 147(3), 567-590.

Devika, K., Jafarian, A., Hassanzadeh, A., Khodaverdi, R. (2016), Optimizing of bullwhip effect and net stock amplification in three-echelon supply chains using evolutionary multi-objective metaheuristics, Annals of Operations Research, 242(2), 457-487.

Disney, S.M. (2001), The production and inventory control problem in Vendor Managed Inventory supply chains. PhD Thesis, Cardiff University, UK.

Disney, S.M., Naim, M.M., Towill, D.R. (1997), Dynamic simulation modeling for lean logistics, International Journal of Physical Distribution and Logistics Management, 27(3), 174-196.

Disney, S.M., Towill, D.R. (2001), A procedure for the optimization of the dynamic response of a Vendor Managed Inventory system, Computers and Industrial Engineering, 43 (1), 7-58.

Dominguez, Roberto, Framinan, Jose M., Cannella, Jose M., (2014) Serial vs. divergent supply chain networks: a comparative analysis of the bullwhip effect, International Journal of Production Research, 52 (7), 2194-2210.

Dooley, K., Yan, T., Mohan, S., Gopalakrishnan, M. (2010), Inventory Management and the Bullwhip Effect During the 2007-2009 Recession: Evidence from the Manufacturing Sector, Journal of Supply Chain Management, 46(1), 12-18.

Huang, S., Batta, R., Nagi, R. (2002) Variable capacity sizing and selection of connections in facility layout, IIE Trans., 35, 49-59.

Kimbrough S.O., Wu, D. J., Zhong, F. (2002), Computer play the beer game: Can artificial agents manage supply chains?, Decision Support Systems, 33, 323-333.

Kristianto, Y., Helo, P., Jiao, J.R., Sandhu, M. (2012), Adaptive fuzzy vendor managed inventory control for mitigating the Bullwhip effect in supply chains, European Journal of Operational Research, 216, 346-355.

Lee, H.L, Padmanabhan, V., Whang, S. (1997a), Information transformation in a supply chain: the bullwhip effect, Management Science, 43 (4), 546-58.

Lee, H.L., Padmanabhan, V., Whang, S. (1997b), The Bullwhip effect in supply chains, Sloan Management Review-Springer, 38 (3), 93-102.

Lee, H.L., Padmanabhan, V., Whang, S. (2004), Information distortion in a supply chain: the bullwhip effect, Management Science, 50 (12), 1875-1886.

Lee, H.L., So, K.C., Tang, C.S. (2000), The value of information sharing in a two level supply chain, Management Science, 46 (5), 628-643.

Li, C. (2012), Controlling the bullwhip effect in a supply chain system with constrained information flows, Applied Mathematical Modelling, 37, 4(15), 1897-1909.

Lin, W.J., Zhi-Bin Jiang, Ran Liu, Lei Wang, (2014), The bullwhip effect in hybrid supply chain, International Journal of Production Research, 52(7), 2062-2084.

Metters, R. (1997), Quantifying the bullwhip effect in supply chains, Journal of Operations Management, 25(2), 89-100. 
Nienhaus, J., Ziegenbein, A., Schoensleben, P. (2006), How Human Behaviour Amplifies the Bullwhip Effect-A Study Based on the Beer Distribution Game Online, Production, Planning and Control, 17(6), 547-557.

Niranjan, T., Metri, A., Aggarwal, V. (2009), The Behavioural Causes of the Bullwhip Effect: Breaking the Mould, International Journal of Services and Operations Management, 5(3), 350-374.

O’Donnell, T., Maguire, L., McIvor, R., Humphreys, P. (2006), Minimization of bullwhip effect in a supply chain using genetic algorithms, International Journal of Production Research, 44(8) 1523-1543.

Oliva, R., Goncalves, P. (2005), Behavioral Causes of the Bullwhip Effect: "Satisfying” Policies with Limited Information Cues, http://web.mit.edu/ paulopg/www/OG_Overreaction.pdf.

Ouyang, Y., Daganzo, C. (2006), Characterization of the Bullwhip Effect in Linear, TimeInvariant Supply Chains: Some Formulae and Tests, Management Science, 52(10), 1544-1556.

Passino, K.M. (2002), Biomimicry of bacterial foraging for distributed optimization and control, IEEE Control System Magazine, 22(3), 52-67.

Seles, B.M.R.P., de Sousa Jabbour, A.B.L., Jabbour, C.J.C., Dangelico, R.M., (2016), The green bullwhip effect, the diffusion of green supply chain practices, and institutional pressures: Evidence from the automotive sector, International Journal of Production Economics, 182, 342-355.

Shan, J., Yang, S., Yang, S., Zhang, J. (2013), An Empirical Study of the Bullwhip Effect in China, Production and Operations Management, doi: 10.1111/poms.12034.

Shukla, N., Kiridena, S., (2016), A fuzzy rough sets-based multi-agent analytics framework for dynamic supply chain configuration, International Journal of Production Research, 54(23), 6984-6996.

Singh, A., Mishra, N., Ali, S.I., Shukla, N., Shankar, R. (2015), Cloud computing technology: reducing carbon footprint in beef supply chain, International Journal of Production Economics, 164, 462-471.

Simchi-Levi, D., Kaminsky, P., Simchi-Levi, E, Shankar, R. (2008), The value of information, In Designing and Managing the Supply Chain: Concepts, Strategies, and Case Studies, McGrawHill Education, 147-185.

Sterman, J.D. (1989), Modeling Managerial behaviour: Misperceptions of feedback in a dynamic decision making experiments, Management Science, 35(3), 321-339.

Tiwari, M. K., Saha, J., Mukhopadhyay, S. K. (2006), Heuristic Solution Approaches for Combined-Job Sequencing and Machine Loading Problem in Flexible Manufacturing Systems, International Journal of Advanced Manufacturing Technology, 31, 716-730.

Tyagi, S. K., Yang, K., Verma, A., (2013), Non-discrete ant colony optimisation (NdACO) to optimise the development cycle time and cost in overlapped product development, International Journal of Production Research, 51 (2), 346-361.

Tyagi, S. K., Yang, K., Tyagi, A., Dwivedi, S. N. (2011), Development of a fuzzy goal programming model for optimization of lead time and cost in an overlapped product development project using a gaussian adaptive particle swarm optimization-based approach, Eng. Appl. Ai, 24 (5),866-879

Verma, A., Shukla, N., Tyagi, S., Mishra, N. (2014), Stochastic modelling and optimisation of multi-plant capacity planning problem, International Journal of Intelligent Engineering Informatics, 2(2), 139-165.

Yan, D.W., Katok, E. (2006), Learning, communication and the bullwhip effect, Journal of Operations Management, 24, 839-850.

Yungao, M., Nengmin, W., Ada, C., Yufei, H., Jinpeng, X. (2012), The bullwhip effect on productorders and inventory: a perspective of demand forecasting techniques, International Journal of Production Research, 51 (1), 281-302. 


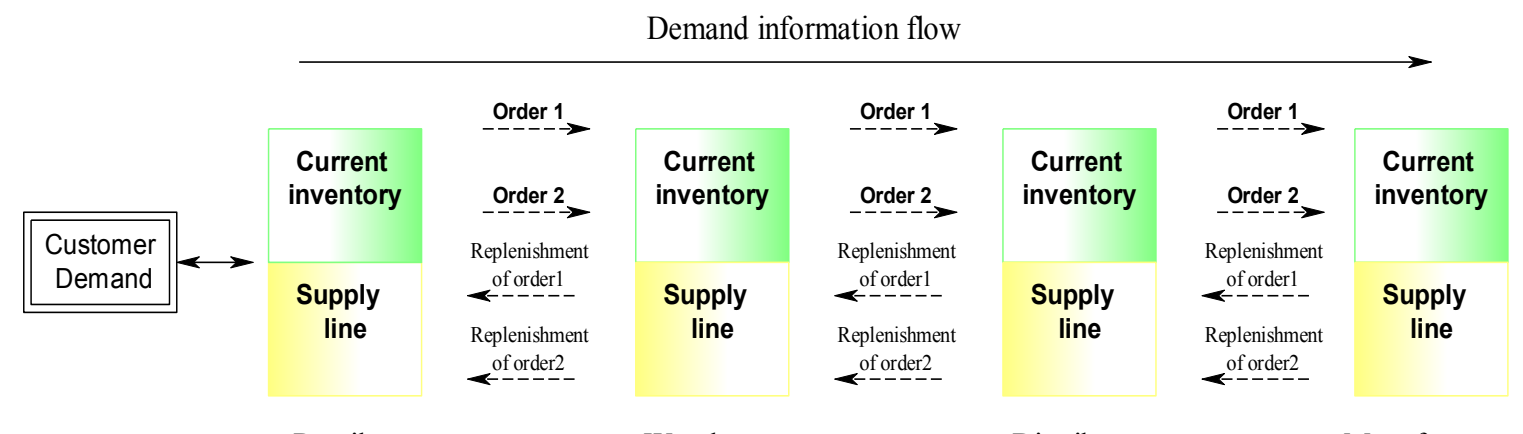

Retailer Warehouse $\quad$ Distributor $\quad$ Manufacturer

Product flow

Figure 1: Multi-stage serial Supply Chain Network

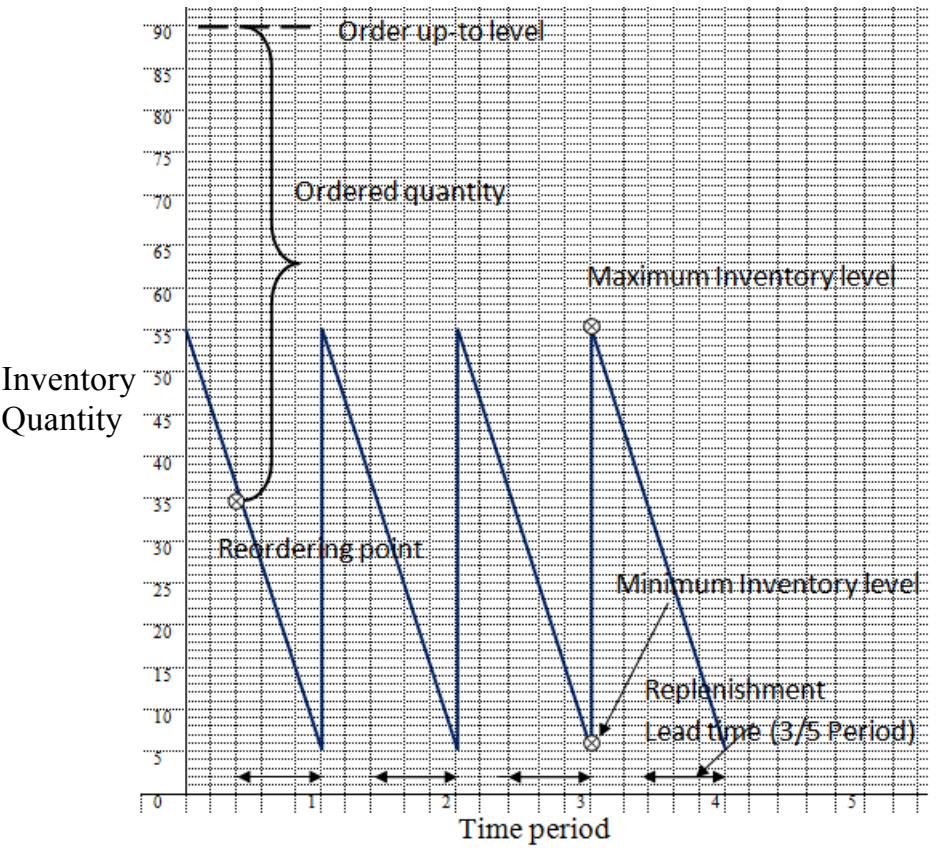

(a)

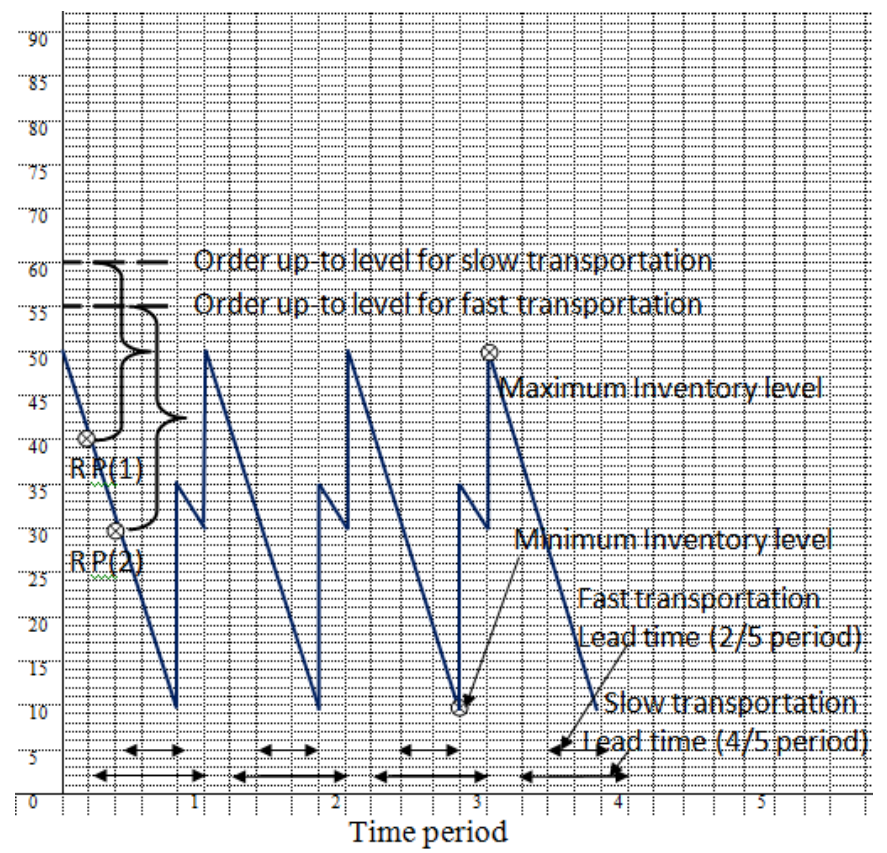

(b)

Figure 2: (a) Graphical representation of the traditional fixed order-up-to level inventory model for a simple periodic replenishment scenario where the consumption rate is constant; (b) Graphical representation of the multiple order-up-to policy (two order-up-to levels) based inventory model for a simple periodic replenishment scenario where the consumption rate is constant two modes of transportation available. (consumption rate is equal in both the cases) 


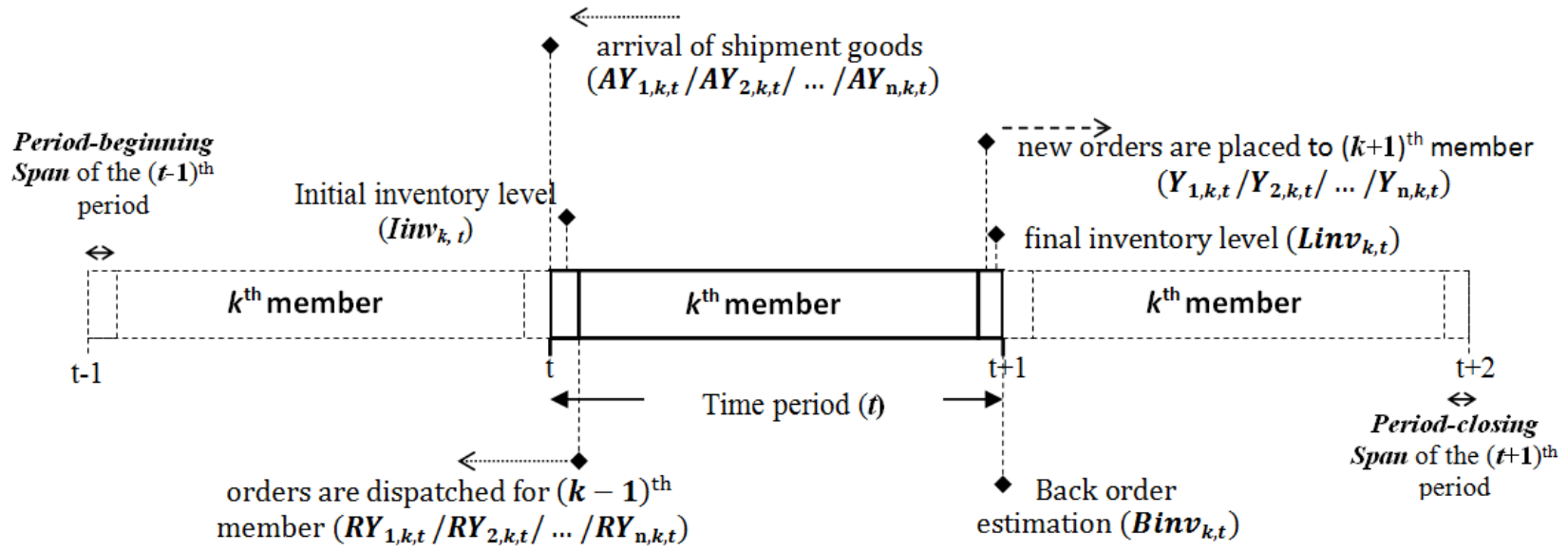

Figure 3: Representation of incidents occur at $k^{\text {th }}$ stage during the time period $\boldsymbol{t}$ (on time scale the incidents are shown in sequence)

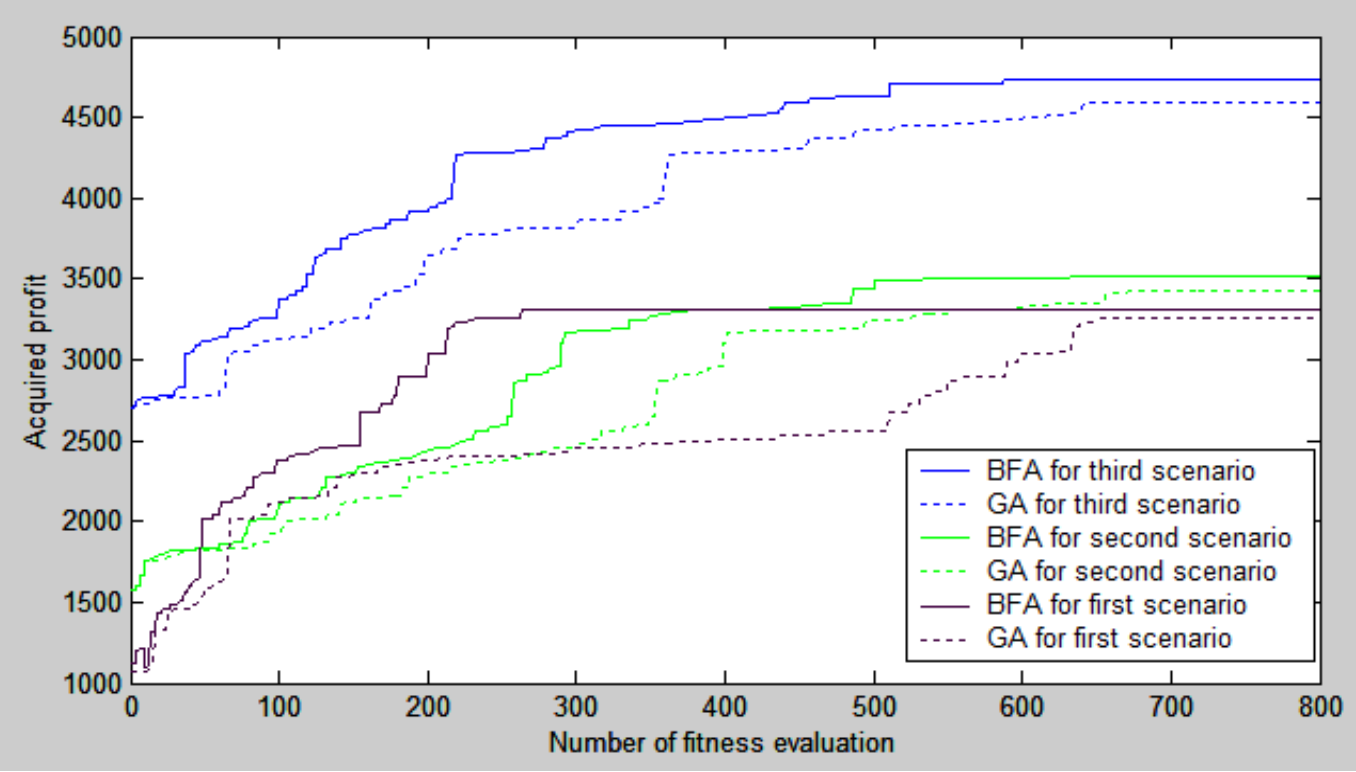

Figure 4: Convergence curve of BFA against GA applied for all of the three types of transportation scenarios 


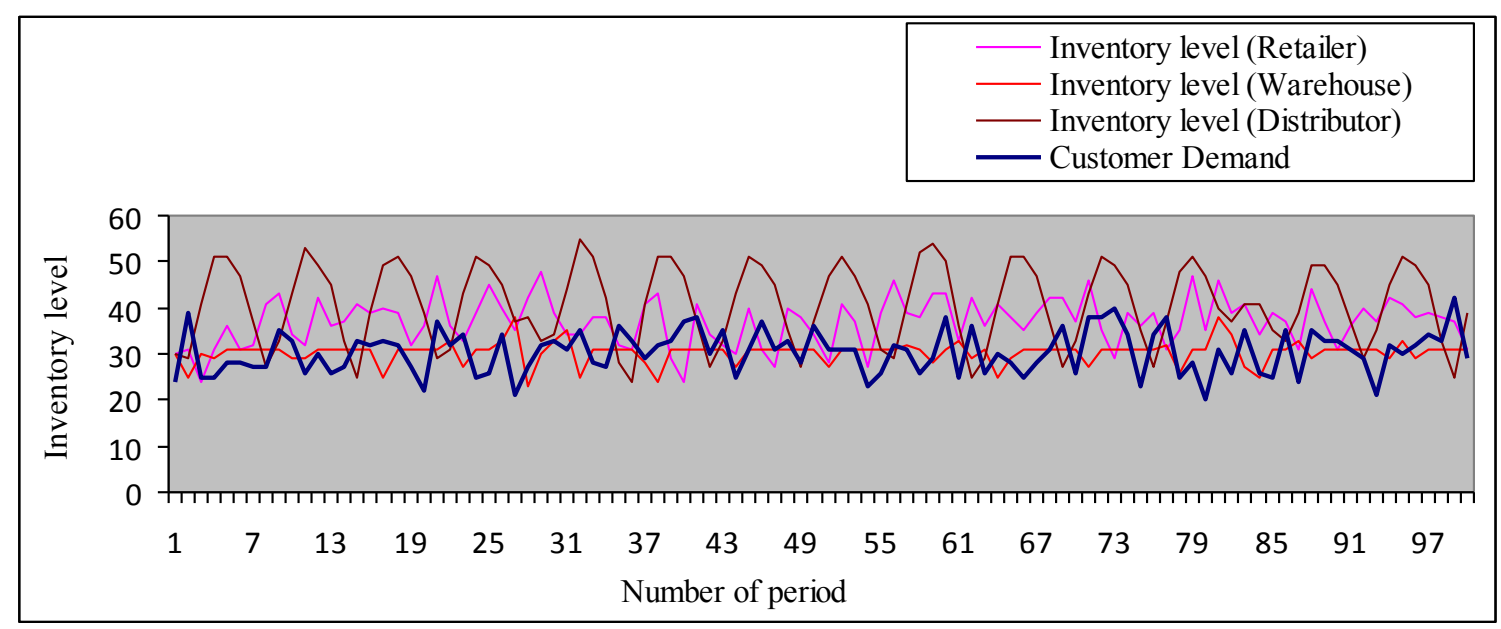

Figure 5: Response of SC in terms of inventory level at the different stages

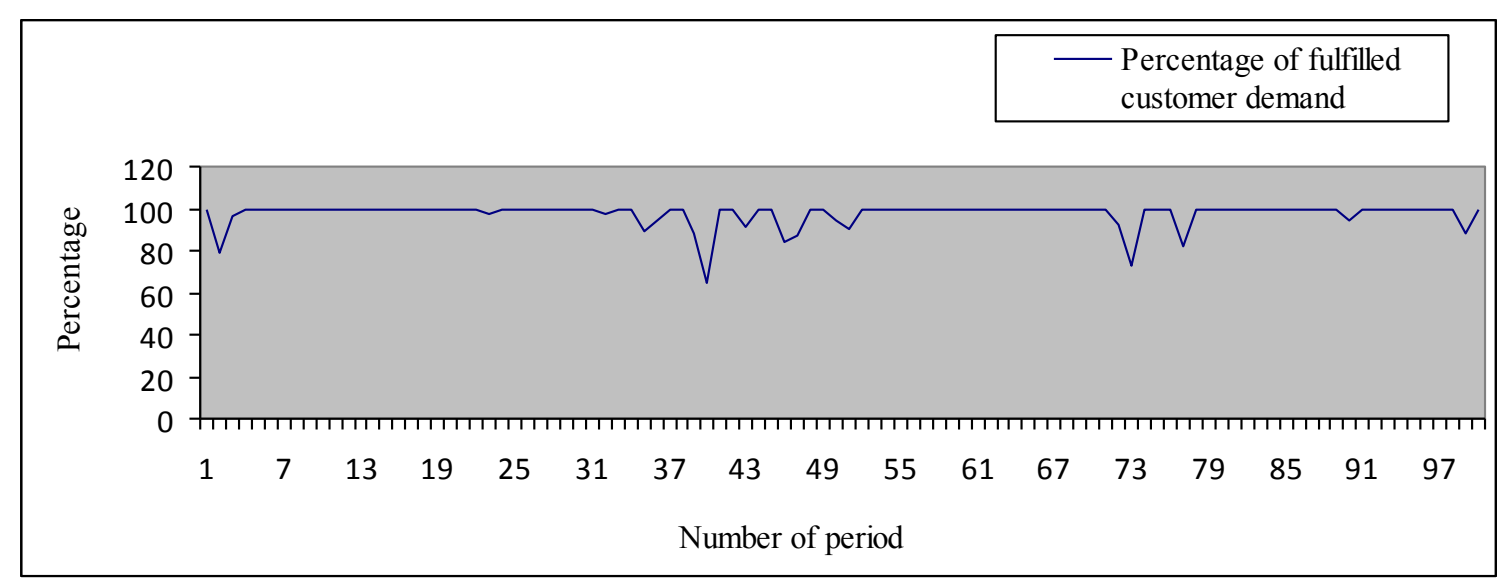

Figure 6: Response of SC in terms of fulfilled customer demand

\begin{tabular}{|c|c|c|}
\hline \multicolumn{3}{|c|}{ Table 1: Result of the performed experiments considering slow transportation ( First scenario) } \\
\hline Experiment & Maximum Profit & Optimum order-up-to levels \\
\hline $\mathbf{1}$ & 3451 & $<34,36,37>$ \\
\hline $\mathbf{2}$ & 3190 & $<32,33,37>$ \\
\hline $\mathbf{3}$ & 3510 & $<32,31,35>$ \\
\hline $\mathbf{4}$ & 3444 & $<32,31,35>$ \\
\hline $\mathbf{5}$ & 3766 & $<32,31,35>$ \\
\hline $\mathbf{6}$ & 3346 & $<32,31,35>$ \\
\hline $\mathbf{7}$ & 4392.1 & $<33,30,32>$ \\
\hline $\mathbf{8}$ & 3163.5 & $<32,33,33>$ \\
\hline $\mathbf{9}$ & 3323 & $<32,34,35>$ \\
\hline $\mathbf{1 0}$ & 3544 & $<32,34,35>$ \\
\hline $\mathbf{1 1}$ & 3490 & $<33,33,34>$ \\
\hline $\mathbf{1 2}$ & 3712 & $<34,35,36>$ \\
\hline
\end{tabular}




\begin{tabular}{|l|c|c|}
\hline $\mathbf{1 3}$ & 3611.9 & $<34,35,36>$ \\
\hline $\mathbf{1 4}$ & 3405.1 & $<34,35,36>$ \\
\hline $\mathbf{1 5}$ & 3492 & $<34,35,36>$ \\
\hline $\mathbf{1 6}$ & 3305 & $<33,33,34>$ \\
\hline $\mathbf{1 7}$ & 3481.2 & $<33,33,35>$ \\
\hline $\mathbf{1 8}$ & 3543.7 & $<34,35,35>$ \\
\hline $\mathbf{1 9}$ & 3420.1 & $<34,35,35>$ \\
\hline $\mathbf{2 0}$ & 3643.0 & $<34,35,35>$ \\
\hline
\end{tabular}

Table 2: Result of the performed experiments considering fast transportation (Second scenario)

\begin{tabular}{|c|c|c|}
\hline Experiment & Maximum Profit & Optimum order-up-to levels \\
\hline $\mathbf{1}$ & 3360 & $<34,36,37>$ \\
\hline $\mathbf{2}$ & 3711 & $<33,30,32>$ \\
\hline $\mathbf{3}$ & 3665 & $<34,33,37>$ \\
\hline $\mathbf{4}$ & 3551 & $<34,31,37>$ \\
\hline $\mathbf{5}$ & 3447 & $<33,30,34>$ \\
\hline $\mathbf{6}$ & 3611 & $<35,32,35>$ \\
\hline $\mathbf{7}$ & 3348 & $<33,31,35>$ \\
\hline $\mathbf{8}$ & 3467 & $<30,32,36>$ \\
\hline $\mathbf{9}$ & 3336 & $<30,32,33>$ \\
\hline $\mathbf{1 0}$ & 3515.1 & $<33,31,35>$ \\
\hline $\mathbf{1 1}$ & 3460.6 & $<33,31,35>$ \\
\hline $\mathbf{1 2}$ & 3400 & $<30,32,36>$ \\
\hline $\mathbf{1 3}$ & 3601.9 & $<33,31,35>$ \\
\hline $\mathbf{1 4}$ & 3455.1 & $<32,31,34>$ \\
\hline $\mathbf{1 5}$ & 3555.2 & $<32,31,34>$ \\
\hline $\mathbf{1 6}$ & 3732.8 & $<34,33,37>$ \\
\hline $\mathbf{1 7}$ & 3471.8 & $<34,31,37>$ \\
\hline $\mathbf{1 8}$ & 3398.2 & $<33,32,34>$ \\
\hline $\mathbf{1 9}$ & 3666.1 & $<32,33,34>$ \\
\hline $\mathbf{2 0}$ & 3451.2 & $<34,36,37>$ \\
\hline
\end{tabular}

Table 3: Result of the performed experiments considering utilization of both transportation (Third scenario)

\begin{tabular}{|c|c|c|}
\hline Experiment & Maximum Profit & Optimum order-up-to levels \\
\hline $\mathbf{1}$ & 4361.5 & $<14,10,17,41,30,36>$ \\
\hline $\mathbf{2}$ & 4515.92 & $<10,10,11,43,31,36>$ \\
\hline $\mathbf{3}$ & 5015.1 & $<10,10,11,43,31,36>$ \\
\hline $\mathbf{4}$ & 4550.6 & $<10,10,13,43,31,37>$ \\
\hline $\mathbf{5}$ & 4508.96 & $<12,10,14,41,30,37>$ \\
\hline $\mathbf{6}$ & 4601.9 & $<12,10,14,41,30,37>$ \\
\hline $\mathbf{7}$ & 4455.1 & $<10,10,11,33,29,35>$ \\
\hline $\mathbf{8}$ & 4491.92 & $<10,10,11,33,29,35>$ \\
\hline $\mathbf{9}$ & 4305.96 & $<10,10,11,33,29,35>$ \\
\hline $\mathbf{1 0}$ & 4732.351 & $<10,10,14,43,31,41>$ \\
\hline $\mathbf{1 1}$ & 4517.73 & $<10,10,14,43,31,41>$ \\
\hline
\end{tabular}




\begin{tabular}{|l|c|l|}
\hline $\mathbf{1 2}$ & 4747.966 & $<10,10,14,43,31,41>$ \\
\hline $\mathbf{1 3}$ & 4795.146 & $<10,10,14,43,31,41>$ \\
\hline $\mathbf{1 4}$ & 4591.314 & $<10,10,14,43,31,41>$ \\
\hline $\mathbf{1 5}$ & 5190.5 & $<10,10,14,43,31,41>$ \\
\hline $\mathbf{1 6}$ & 4539.8 & $<14,10,17,41,30,36>$ \\
\hline $\mathbf{1 7}$ & 4471.8 & $<13,10,11,40,31,37>$ \\
\hline $\mathbf{1 8}$ & 4553.7 & $<13,10,11,38,31,37>$ \\
\hline $\mathbf{1 9}$ & 4470.1 & $<11,10,11,41,31,39>$ \\
\hline $\mathbf{2 0}$ & 4603.0 & $<11,13,12,41,31,39>$ \\
\hline
\end{tabular}

Table 5:Parameter values related to the data sets of problem

\begin{tabular}{|c|c|c|}
\hline Classification & $\begin{array}{c}\text { Number of transportation } \\
\text { facilities }\end{array}$ & Number of players \\
\hline Very small (VS) & $2-3$ & $3-6$ \\
\hline Small (S) & $4-5$ & $7-10$ \\
\hline Large (L) & $6-7$ & $11-14$ \\
\hline Very large (VL) & $8-9$ & $15-18$ \\
\hline
\end{tabular}

Table 6:Computational results for very small and small sized data set

\begin{tabular}{|c|c|c|c|c|c|}
\hline \multicolumn{2}{|c|}{ Results for very small sized data set } & \multicolumn{2}{c|}{ Results for small sized data set } \\
\hline $\begin{array}{c}\text { Number } \\
\text { transportation } \\
\text { facilities }\end{array}$ & $\begin{array}{c}\text { Number of } \\
\text { Players }\end{array}$ & $\begin{array}{c}\text { Heuristic } \\
\text { gap }\end{array}$ & $\begin{array}{c}\text { Number } \\
\text { transportation } \\
\text { facilities }\end{array}$ & $\begin{array}{c}\text { Number of } \\
\text { Players }\end{array}$ & $\begin{array}{c}\text { Heuristic } \\
\text { gap }\end{array}$ \\
\hline 2 & 3 & 1.234 & 4 & 7 & 0.987 \\
\hline 2 & 4 & 2.114 & 4 & 8 & 1.677 \\
\hline 3 & 5 & 1.768 & 5 & 9 & 2.104 \\
\hline 3 & 6 & 1.904 & 5 & 10 & 1.346 \\
\hline
\end{tabular}

Table 7: Computational results for large and very large sized data set

\begin{tabular}{|c|c|c|c|c|c|}
\hline \multicolumn{2}{|c|}{ Results for large sized data set } & \multicolumn{2}{c|}{ Results for very large sized data set } \\
\hline $\begin{array}{c}\text { Number } \\
\text { transportation } \\
\text { facilities }\end{array}$ & $\begin{array}{c}\text { Number of } \\
\text { Players }\end{array}$ & $\begin{array}{c}\text { Heuristic } \\
\text { gap }\end{array}$ & $\begin{array}{c}\text { Number } \\
\text { transportation } \\
\text { facilities }\end{array}$ & $\begin{array}{c}\text { Number of } \\
\text { Players }\end{array}$ & $\begin{array}{c}\text { Heuristic } \\
\text { gap }\end{array}$ \\
\hline 6 & 11 & 2.773 & 8 & 15 & 1.056 \\
\hline 6 & 12 & 1.855 & 8 & 16 & 2.834 \\
\hline 7 & 13 & 2.379 & 9 & 17 & 2.536 \\
\hline 7 & 14 & 2.757 & 9 & 18 & 1.916 \\
\hline
\end{tabular}

Table 8: Average heuristic gap for different problem sizes

\begin{tabular}{|c|c|c|c|}
\hline & Low & High & Average \\
\hline Very Small & 1.674 & 1.836 & 1.755 \\
\hline Small & 1.332 & 1.725 & 1.528 \\
\hline Large & 2.314 & 2.568 & 2.441 \\
\hline Very Large & 1.945 & 2.226 & 2.085 \\
\hline
\end{tabular}


Table 9: Intermediate values of the two ways ANOVA test without replication

\begin{tabular}{|l|l|l|l|l|}
\hline SUMMARY & Count & Sum & Average & Variance \\
\hline Row 1 & 2 & 3.51 & 1.755 & 0.013122 \\
\hline Row 2 & 2 & 3.057 & 1.5285 & 0.077224 \\
\hline Row 3 & 2 & 4.882 & 2.441 & 0.032258 \\
\hline Row 4 & 2 & 4.171 & 2.0855 & 0.03948 \\
\hline & & & & \\
\hline Column 1 & 4 & 7.265 & 1.81625 & 0.173022 \\
\hline Column 2 & 4 & 8.355 & 2.08875 & 0.148238 \\
\hline
\end{tabular}

Table 10: Results of ANOVA test

\begin{tabular}{|c|c|c|c|c|c|c|}
\hline $\begin{array}{l}\text { Source of } \\
\text { Variation }\end{array}$ & SS & df & MS & $\mathrm{F}$ & P-value & F crit \\
\hline Rows & 0.950207 & 3 & 0.316736 & 70.00973 & 0.002825 & 9.276628 \\
\hline Columns & 0.148513 & 1 & 0.148513 & 32.82649 & 0.010555 & 10.12796 \\
\hline Error & 0.013573 & 3 & 0.004524 & & & \\
\hline Total & 1.112292 & 7 & & & & \\
\hline
\end{tabular}

